\title{
Chondrosarcoma of the larynx: Report of one case and review of the literature
}

\author{
Jawad Hasnaoui*, Said Anajar, Lkhdim Mouna, Reda Abada, Sami Rouadi, Mohammed Roubal and Mohammed Mahtar \\ ENT Department, Face and Neck Surgery, Hospital August, 20'1953, University Hospital Centre IBN ROCHD, Casablanca, Morrocco
}

\begin{abstract}
Laryngeal chondrosarcoma is a rare tumor whose treatment is essentially surgical. The prognosis generally favorable depends mainly on the histological grade.

The objective of this report is to describe, from this case, clinical, radiological and histological features of laryngeal chondrosarcoma, and discuss its therapeutic management.
\end{abstract}

\section{Introduction}

The laryngeal chondrosarcoma is a rare histological type with less than $1 \%$ of laryngeal cancer. The pathogenesis is still unknown $[1,2]$. Diagnosis can be difficult, especially in histology. Surgery is the best treatment and may vary from an endoscopic surgery to partial surgery or total laryngectomy, depending on the extension and the histological grade of the cancer [3-5].

The prognosis is usually good especially for the low-grade chondrosarcoma $[6,7]$.

This study reports a recent clinical case and analyzes the epidemiological, clinical, histological, radiological, and treatment of this rare location of chondrosarcoma.

\section{Case report}

A 46-year-old North African man has this past 6 months dysphonia that was complicated by laryngeal dyspnea that required an emergency tracheotomy. Clinical examination found a patient in good general condition with Karnofsky Index 100\%, well maintained tracheostomy cannula surrounded by normal skin and absence of lymphadenopathy. A systemic examination was unremarkable. The flexible endoscopy showed a laryngeal sector obstructed by a large diffuse supraglottic process looks bumpy in places (Figure 1).

Computed tomography showed a tumor process centered on the two arytenoid (Figure 2) which are unrecognizable with a dual chondroid and tissular component with a calcification. This process extends the vocal folds, ventricles and ventricular strips on both sides, noted the absence of cervical lymphadenopathy.

Direct Laryngoscopy showed a diffuse supraglottic neoformation, covered with a lining inflammatory. The exploration of the two floors glottic and subglottic is impossible.

Histological study of biopsy done at a low grade, well differentiated chondrosarcoma and classed T4N0M0 (Figure 3).

Total laryngectomy without lymphadenectomy was planned. Histological study of the workpiece Laryngectomy showed low grade chondrosarcoma invading the thyroid cartilage and the opposite muscles with healthy resection limits of the trachea and epiglottis.

The postoperative course was uncomplicated. At 13 months followup, there was no recurrence.

\section{Discussion}

The laryngeal chondrosarcoma is rare, with less than $1 \%$ of laryngeal cancer. But it is the most common mesenchymal cancers. Predilection site is the cricoid cartilage (75\%) followed by the thyroid cartilage (17\%), the arytenoid (5\%) and epiglottis (2\%) [8]. It usually occurs in patients between 50 and 70 years, mainly men.

The exact pathogenesis remains to be elucidated; some hypotheses attribute this condition to 3 local lesions, abnormal ossification, chronic inflammation and metabolic disorders related to old age [9].

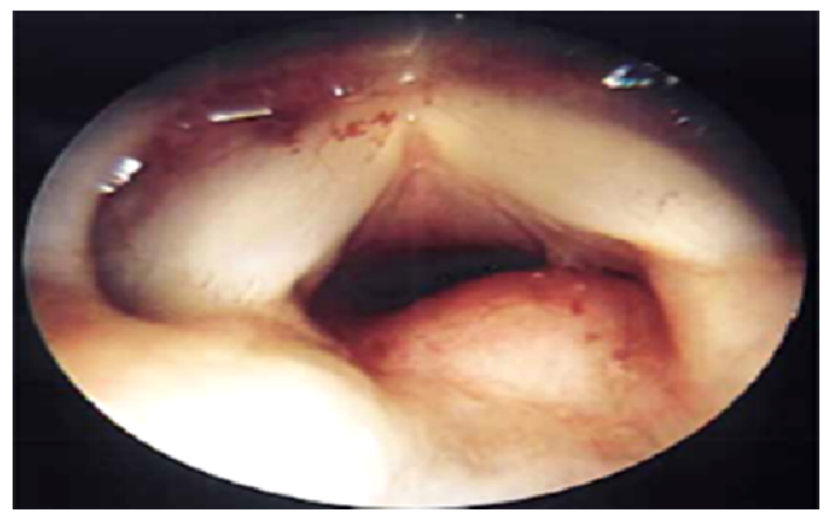

Figure 1. Endoscopic examination shown laryngeal sector obstructed by a large diffuse supraglottic covered by intact mucosa.

Correspondence to: Jawad Hasnaoui, ENT Department, Face and Neck Surgery, Hospital August, 20'1953, University Hospital Centre IBN ROCHD, 6, Street lahssen ELAARJOUN quartier des hopitaux, Casablanca, Morroco, Tel: 00212675601663; E-mail: jawad.hasnaoui86@gmail.com

Key words: chondrosarcoma, larynx, laryngectomy

Received: February 27, 2017; Accepted: March 16, 2017; Published: March 20, 2017 


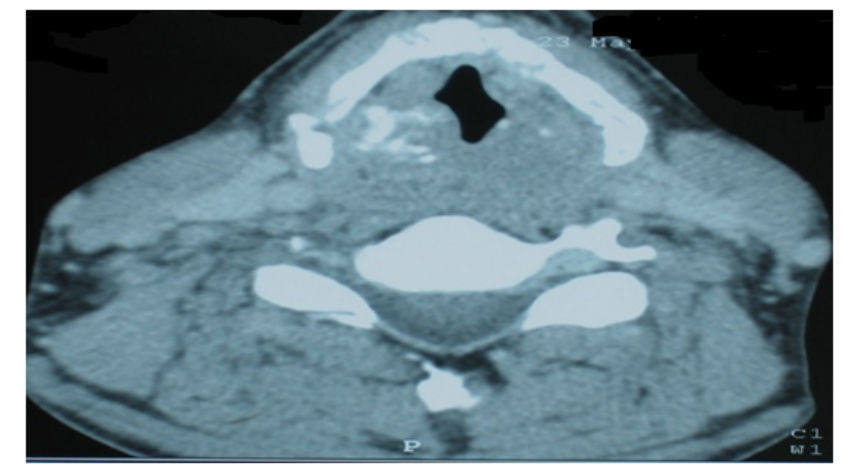

Figure 2. CT scan showed a tumor process centered on the two arytenoid which are unrecognizable with a dual chondroid and tissular component with a calcification.

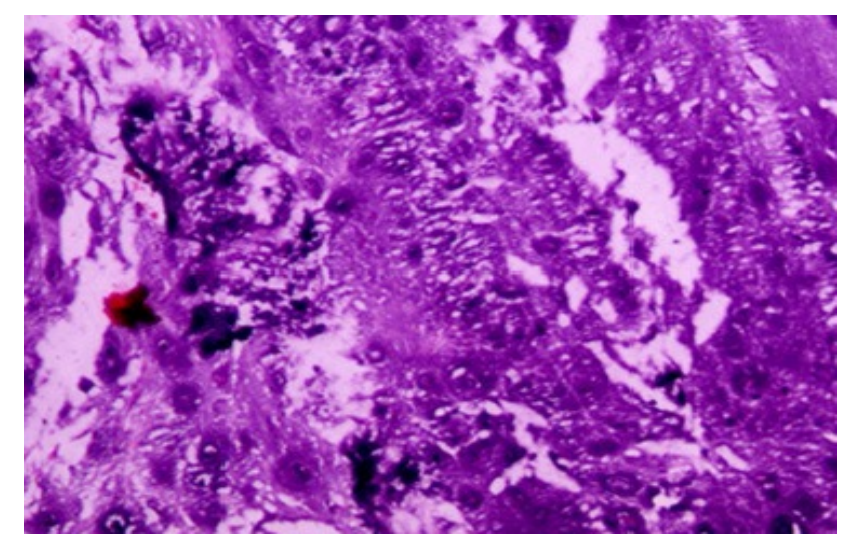

Figure 3. Histopathology showing lobular and patchily hypercellularproliferation of atypical chondrocytes. Magnification $\times 200$.

Dysphonia is the main clinical sign. While dyspnea associated when the cancer increases in size, dysphagia is rarely present. A neck mass can also be revealing. In direct laryngoscopy, swelling submucosa and mucosa intact can be detected.

Moreover, the first sign of the posterior cricoid involvement may be the stiffness of the vocal cords, due to the blockage of the cricothyroid articulation arytenoidic and not because of the infiltration of the recurrent nerve $[10,11]$.

The computer tomography is the examination of choice to analyze the nature, location and extension of cartilaginous tumors. These tumors, centered on cartilage, are well-defined contours, hypodense with moderate contrast enhancement. Calcifications characteristics are found in $80 \%$ of cases appearance like "Popcorn". The CT scan also determines the degree of obstruction of the laryngeal sector and relations with adjacent structures of the tumor.

MRI is less specific but to better clarify the extension and the relationship of the tumor to the surrounding structures [12]. Although the imaging may indicate the origin of the cartilaginous lesion, but does not distinguish the chondroma of low grade chondrosarcoma.

Diagnosis of chondrosarcoma is given certainty by histological analysis. The histological appearance of the mesenchymal cancer was classified by Evans et al. [6] in different malignancy grades: a malignant form of low grade (first level) is characterized by chondrocytes in small, dense nuclei, binucleated cellules, mitotic activity and low cellularity. The intermediate form and the high-grade malignant type are characterized by increased cellularity, many binucleated and multinucleated cells and numerous mitotic figures $[6,13]$.
Surgery is the best treatment for these tumors, it must allow the eradication of cancer with sufficient safety margins and in the case of low-grade, must be functional and conservative $[3,14]$. Chondrosarcoma is considered less sensitive to radiotherapy. It may nevertheless be considered when surgery is impossible or if the excision is incomplete [15].

Most authors, however, agree that there is little evidence for postoperative adjuvant radiotherapy after complete resection [16]. Chemotherapy has no curative role [17].

The major prognostic factors are histologic grade, location, extent and quality of the initial resection. Local recurrence of chondrosarcoma is frequent. They have low metastatic potential. Lung and cervical lymph nodes are the most commonly affected sites [18].

\section{Conclusion}

Laryngeal chondrosarcoma is a rare tumor. Imaging-based scanner's role is to clarify the seat and tumor extension, it does not distinguish between chondroma and low-grade chondrosarcoma. This distinction remains as histological dilemma. The treatment is surgical. The prognosis is generally good, and basically depends on the histological grade.

\section{Acknowledgement}

None

\section{Conflicts of interest}

All the authors have no personal or financial conflicts of interest regard this case report.

\section{Funding}

No sources of funding to declare.

\section{References}

1. Burggraaff BA, Weinstein GS (1992) Chondrosarcoma of the larynx. Ann OtolRhinolLaryngol101: 183-184.[Crossref]

2. Rinaggio J, Duffey D, McGuff HS (2004) Dedifferentiated chondrosarcoma of the larynx. Oral Surg Oral Med Oral Pathol Oral Radiol Endod 97: 369-375.[Crossref]

3. Verhulst J, Gal M, Carles D, Saurel J, Teixeira Scarpin M, et al. (1996) [Chondroma and chondrosarcoma of the larynx: apropos of 4 cases]. Rev Laryngol Otol Rhinol (Bord) 117: 183-188.[Crossref]

4. Koka VN, Veber F, Haguet JF, Rachinel O, Freche C, et al. (1995) Chondrosarcoma of the larynx. J LaryngolOtol109: 168-170.[Crossref]

5. Miloundja J, Lescanne E, Garand G, Vinikoff-Sonier C, Beutter P, et al. (2005) [Chondrosarcoma of the cricoid]. Ann Otolaryngol Chir Cervicofac 122: 91-96. [Crossref]

6. Evans HL, Ayala AG, Romsdahl MM (1977) Prognostic factors in chondrosarcoma of bone: a clinicopathologic analysis with emphasis on histologic grading. Cancer40: 818-831.[Crossref]

7. Neel HB 3rd, Unni KK (1982) Cartilaginous tumors of the larynx: a series of 33 patients. Otolaryngol Head Neck Surg90: 201-207.[Crossref]

8. Ferlito A, Nicolai P, Montaguti A, Cecchetto A, Pennelli N (1984) Chondrosarcoma of the larynx: review of the literature and report of three cases. Am J Otolaryngol 5: 350-359.[Crossref]

9. Neis PR, McMahon MF, Norris CW (1989) Cartilaginous tumors of the trachea and larynx. Ann OtolRhinolLaryngol98: 31-36.[Crossref]

10. Ferlito A (1993) Neoplasm of the larynx. First Edition. Edinburgh: ChurchillLivingstone; 305 .

11. Thomé R, Thomé DC, de la Cortina RA (2001) Long-term follow-up of cartilaginous tumors of the larynx. Otolaryngol Head Neck Surg 124: 634-640.[Crossref] 
12. Oudidi A, Hachimi H, El Alami MN (2005) [Laryngeal chondrosarcoma]. Cancer Radiother 9: 343-346.[Crossref]

13. Evans HL, Ayala AG, Romsdahl MM (1977) Prognostic factors in chondrosarcoma of bone: a clinicopathologic analysis with emphasis on histologic grading. Cancer 40: 818-831.[Crossref]

14. Rinaldo A, Howard DJ, Ferlito A (2000) Laryngeal chondrosarcoma: a 24-year experience at the Royal National Throat, Nose and Ear Hospital. Acta Otolaryngol 120: 680-688.[Crossref]

15. Neel HB 3rd, Unni KK (1982) Cartilaginous tumors of the larynx: a series of 33 patients. Otolaryngol Head Neck Surg 90: 201-207.[Crossref]

16. Thompson LD, Gannon FH (2002) Chondrosarcoma of the larynx: a clinicopathologic study of 111 cases with a review of the literature. Am J SurgPathol 26: 836-851. [Crossref]

17. Jones DA, Dillard SC, Bradford CR, Wolf GT, Prince ME (2003) Cartilaginous tumours of the larynx. J Otolaryngol 32: 332-337.[Crossref]

18. Friedlander PL, Lyons GD (2000) Chondrosarcoma of the larynx. Otolaryngol Head Neck Surg 122: 617.[Crossref]

Copyright: $(02017$ Hasnaoui J. This is an open-access article distributed under the terms of the Creative Commons Attribution License, which permits unrestricted use, distribution, and reproduction in any medium, provided the original author and source are credited. 